\title{
Different Working Parameters of Biomass Processing with the Band Saw out, the Impact of Vibration Frequency and the Rate of Tooth
}

\author{
Jin-Gui GAO ${ }^{1, a}$, Zhao-Fang JIANG ${ }^{2, b,{ }^{*}}$ and De-Jun SHEN ${ }^{3, c}$ \\ 123 BEIHUA UNIVERSITY \\ ajiangzhao_fang@126.com, b675375003@qq.com, c563794663@qq.com \\ *Corresponding author: Zhao-Fang JIANG
}

Keywords: Sawing machine saw blade; vibration; tooth loss; power spectrum; vibration frequency.

\begin{abstract}
The MJ3310B type woodwork sawing machine as the research object, research and processing of biomass materials, and how to determine the band saw off the number of the tooth loss. The use of high precision VibSys Beijing pop vibration analyzer and vibration signal acquisition and processing software under different operating conditions, the acquisition of transverse vibration of band saw blade displacement, and the power spectrum analysis. The analysis shows that: for the MJ3310B type woodworking band sawing machine, use the $125 \mathrm{~mm}$ width of blade, is the main factor affecting the band saw tooth loss: saw wheel speed, weight weight, feed rate. No load when the saw wheel spindle speed, RAM weight, upper and lower saw blade spacing are adjusted to the most appropriate circumstances, determination of transverse vibration frequency between $31 \mathrm{~Hz} \sim 43 \mathrm{~Hz}$, the saw blade has produced at least 1 lost tooth defect; the feed speed under proper cutting of poplar, determination of transverse the vibration frequency is between $33 \mathrm{~Hz} 51 \mathrm{~Hz}$, the saw blade has produced at least 1 lost tooth defect. With the increase of the number of teeth out of band saw blade, saw blade vibration frequency increases, increases from $33 \mathrm{~Hz}$ to $72 \mathrm{~Hz}$. According to the change of transverse band saw blade vibration frequency, can be inferred the number of teeth in the reverse band saw off, which can fault on-line monitoring of band-saw blade.
\end{abstract}

\section{Introduction}

The band saw cutting in biomass materials cutting belongs to the closed state of the cutting edge of the cutting, change is difficult to timely use eyes to observe, determine the time for saw. According to the survey, the biomass materials processing enterprises are using two methods: first, the use of a limited time for sawing. According to the experience of every period of time for saw blade, saw blade with root position with chalk, and then with the help of light to determine the defects; the two is to produce a sound according to the cutting conditions to determine the blade work and tooth loss situation. These two methods are not scientific. To judge the emergence and development of the saw tooth loss is extremely difficult to judge in a timely manner[1].

According to the investigation data, a band saw blade crack research - crack research law and recognition, has not been reported at home and abroad. From the experiment, the result of the judgment of the lost teeth is not seen. In addition, the application of laser interference signal analysis method is not seen[2-6].

In order to improve the wood surface processing quality, and provide scientific basis for the correct judgment of blade replacement time selection. This experiment mainly studies the relationship between the tension, saw wheel speed, feed speed and the development of tooth loss and load during no-load and load.

\section{Main experimental instruments and equipment}

\subsection{Test instrument}

The instruments used in the test are shown in Tab. 1. 
Tab.1 Apparatus and Equipments

\begin{tabular}{|c|c|c|c|}
\hline $\begin{array}{c}\text { Serial } \\
\text { number }\end{array}$ & Device name & model & Manufacturer \\
\hline 1 & $\begin{array}{l}\text { Data acquisition } \\
\text { instrument }\end{array}$ & WS-5942-2-50 & $\begin{array}{l}\text { Beijing century science } \\
\text { and Technology } \\
\text { Development Co., Ltd. }\end{array}$ \\
\hline 2 & Eddy current sensor & HZ-8500 & $\begin{array}{l}\text { Beijing vibration } \\
\text { instrument factory }\end{array}$ \\
\hline 3 & $\begin{array}{l}\text { Woodworking band } \\
\text { sawing machine }\end{array}$ & MJ3310B & $\begin{array}{c}\text { Shenyang light river } \\
\text { woodworking machinery } \\
\text { factory . }\end{array}$ \\
\hline
\end{tabular}

\subsection{Equipment composition and parameters}

\subsubsection{Machine composition}

Test subjects for MJ3310B sports car in Huadian City Huibang wood sawing machine Jilin province. The next round, saw, band saw blade, car, tension mechanism, power system, frame, etc., as shown in Fig.1.

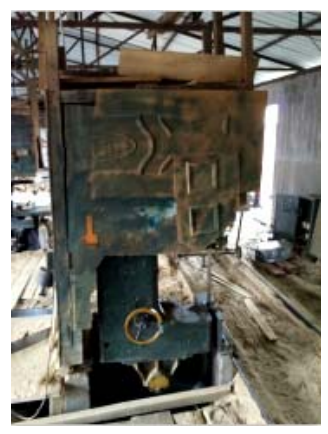

Fig. 1 Bench woodworking band sawing machine Fig.2 Sensor installation locations

\subsubsection{Machine parameters}

Sports equipment: woodworking band sawing machine; Model: MJ3210A; Saw wheel diameter: 1067mm; Saw wheel speed: 700rpm, 800rpm, 900rpm, 1000rpm, 1100rpm; Motor speed: 1400rpm; Blade parameters: the wedge angle is 35.2 degrees, the bandwidth of $125 \mathrm{~mm}$ and $9.81 \mathrm{~mm}$ after the tooth height, angle of 28.8 degrees angle 26 degrees.

\subsubsection{Sensor Installation Position}

Sensor installation position as shown in figure 2. Its location is located in the upper and lower saw card center line and the saw blade width $1 / 2$ intersection point.

\subsubsection{Description of sensor location and actual production}

The installation position of the sensor is shown in Fig.2. The position is located in the upper and lower saw blade width with the center line of intersection card on 1/2.

\section{Test results and analysis}

3.1. Effect of no-load and load under the wheel spindle speed of saw blade vibration falling tooth defects

The band saw ram weight $100 \mathrm{~N}, 550 \mathrm{~mm}$ on the premise of saw blade spacing under the transmission device five by adjusting speed, respectively on the no-load condition without defects 
and produces 1 saw tooth drop defect of saw blade is used for data acquisition, the acquisition data through power spectrum analysis, frequency data finishing plotted in Fig.3; and under the same conditions of sawing wood, the data analysis is finished into curve as shown in Fig.4.

By observing the curve shown in Fig. 3, can be found in sawing machine high-speed operation (more than 1000rpm) when the tooth drop band saw blade vibration frequency almost no change, while in the low speed operation, the contrast is quite obvious, which the band saw the vibration frequency of falling tooth defect rate will be about $10 \mathrm{HZ}$ lower than full band saw the blade vibration frequency, tooth loss rate in $31 \mathrm{~Hz} \sim 43 \mathrm{~Hz}$; through the observation of the curve in Fig. 4 and Fig.5, we can see the characteristics of basically the same, but the load ratio under no-load frequency increased slightly but not significantly increased, probably around $1 \mathrm{~Hz} 2 \mathrm{~Hz}$, tooth loss frequency rate was $33 \mathrm{~Hz} \sim 45 \mathrm{~Hz}$.

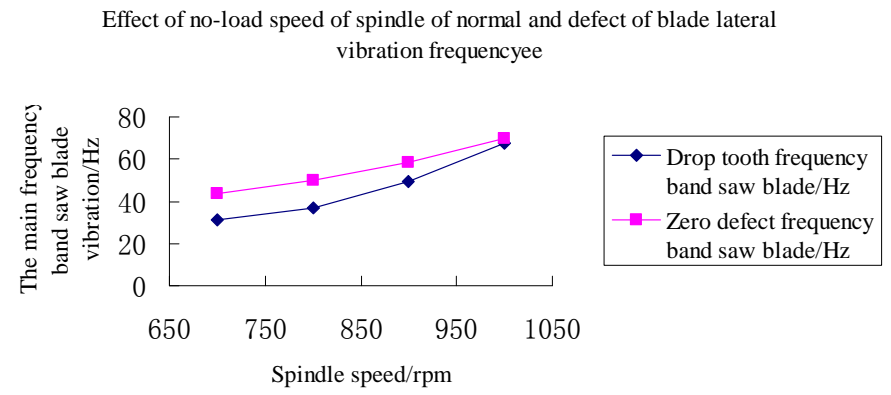

Fig. 3 Effect of no-load speed of spindle of normal and defect of blade lateral vibration frequency

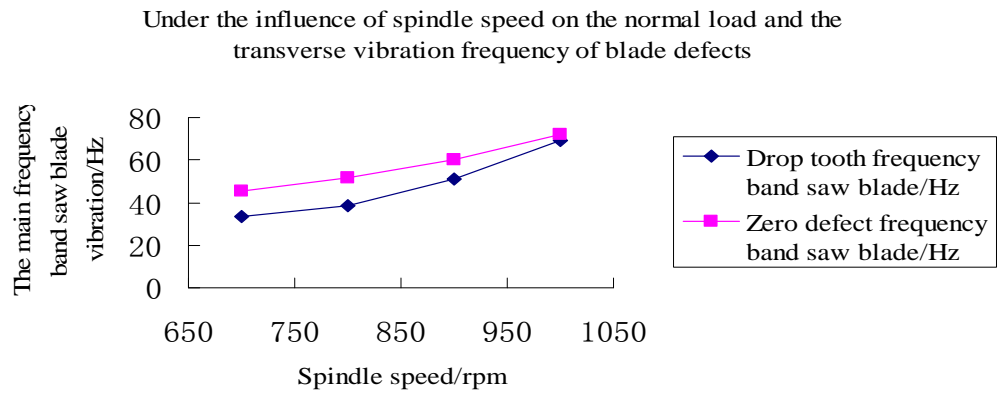

Fig. 4 Under the influence of spindle speed on the normal load and the transverse vibration frequency of blade defects

\subsection{Effect of No-load and Load under the Weight of the Saw Blade Vibration Pressure Lead falls from the Tooth Defects}

In band sawing machine saw wheel spindle speed is 700rpm, the premise saw card spacing of $550 \mathrm{~mm}$, change the five ram weight of load and defect free blade falls from the teeth (1 teeth) defect saw blade for data acquisition, the pressure increases with the weight of the saw and band saw blade Tuo transverse vibration set the data through the power spectrum analysis, frequency data after finishing plotted in Figure 5; and under the same conditions of sawing wood, the data analysis is finished into curve as shown in figure 6.

According to the comparison of frequency curve in Figure 5 shows that the vibration frequency of the blade increases with pressure lump weight, increased, and the vibration frequency of blade in tooth loss after tooth loss than before decreased, decreased to a certain extent tends to be gentle. The vibration frequency of blade tooth loss defect rate was $31 \mathrm{~Hz} 43 \mathrm{~Hz}$; through the observation of the curve in Figure 6 and figure 5, we can see the characteristics of basically the same, but the load ratio under no-load frequency increased slightly but not significantly increased, probably around $1 \mathrm{~Hz} \sim 2 \mathrm{~Hz}$, tooth loss frequency rate was $33 \mathrm{~Hz} \sim 45 \mathrm{~Hz}$. 


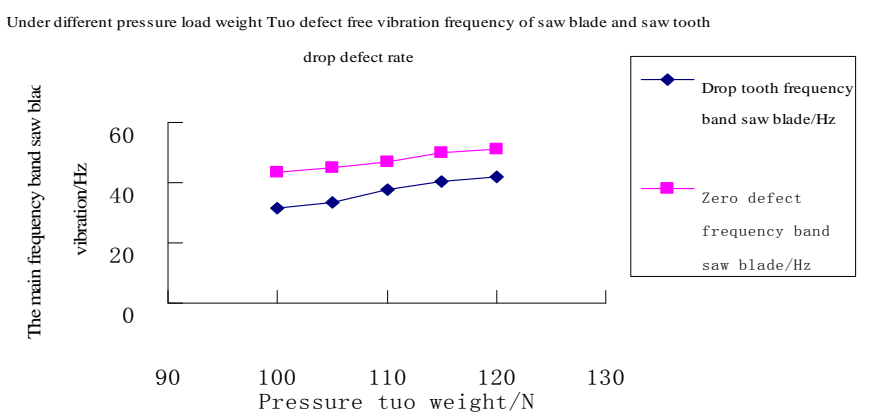

Fig. 5 Under different pressure load weight Tuo defect free vibration frequency of saw blade and saw tooth drop defect rate

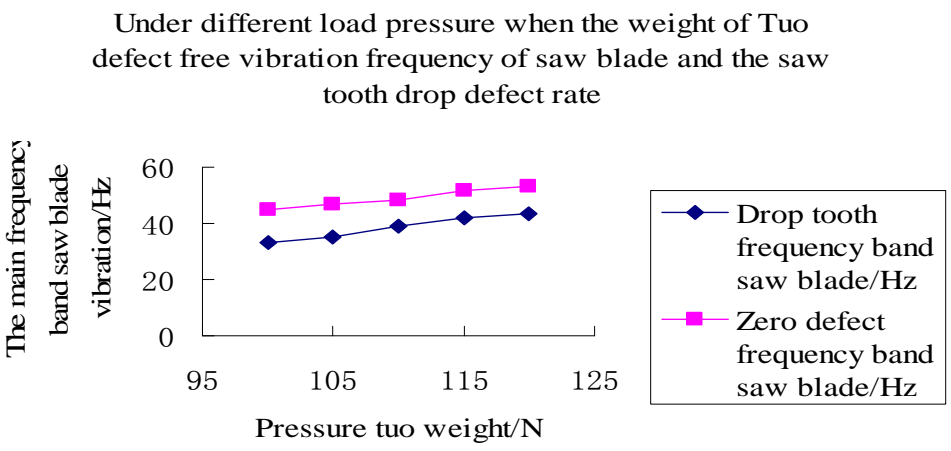

Fig. 6 Under different load pressure when the weight of Tuo defect free vibration frequency of saw blade and the saw tooth drop defect rate

\subsection{Different Saw Blade Cutting Height of Wood Road of Tooth Defect of Blade Vibration Impact}

In determining the saw wheel spindle speed 700rpm, lost 1 teeth, RAM weight $100 \mathrm{~N}$, upper and lower saw blade spacing $550 \mathrm{~mm}$, remote feeding 200MPF, cutting poplar, respectively 20mm, $40 \mathrm{~mm}$ saw sawing Road, $60 \mathrm{~mm}, 80 \mathrm{~mm}$ and $100 \mathrm{~mm}$ level data collection, respectively to collect data and produce a complete blade off the tooth defect now saw blade, cutting kerf at different height by collecting the transverse vibration of saw blade with data through the power spectrum analysis, the frequency data plotted after finishing 7.

Fig.7 shows that the different height of the kerf sawing wood frequency did not change significantly, almost no change, but the defect free blade frequency more stable

Different cutting saw blade and blade height without defects

have fallen tooth defect rate of vibration frequency

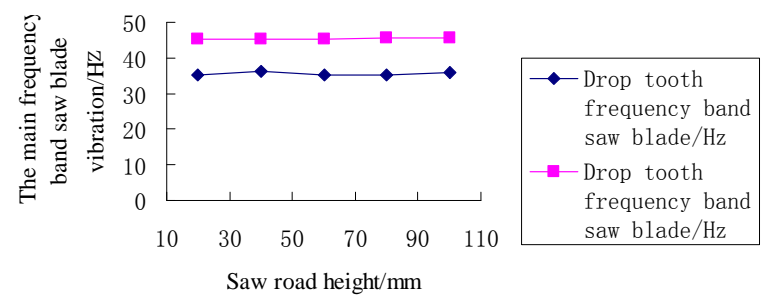

Fig. 7 Different cutting kerf height defect free saw blade and the saw blade vibration frequency have fallen tooth defect rate

\subsection{The Load Under the Influence of Different Feeding Speed on the Condition of Different Frequency Band Saw Blade}


Band sawing machine spindle speed is $700 \mathrm{rpm}$, Pressure lead weight is $100 \mathrm{~N}$, pressure fluctuation saw card a distance of $550 \mathrm{~mm}$, processing under the premise of elm $15 \mathrm{~mm}$, feeding speed change five times, respectively on the full blade and drop tooth saw blade (a tooth) defects for data collection, through the power spectrum analysis, get the frequency data after finishing drawing into curve as shown in Fig.8.

Different feeding speed on different conditions the influence of vibration frequency band saw blade

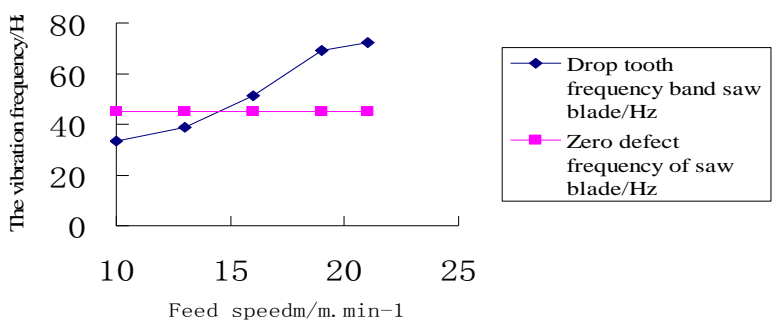

Fig.8 Different feeding speed on the defect free saw blade and falls from the effect of tooth defect of saw blade vibration frequency.

Fig. 8 shows that with the increase of feed speed, complete blade vibration frequency increases, the numerical increase from $45 \mathrm{~Hz}$ to $51 \mathrm{~Hz}$, the frequency band saw blade tooth drop defect rate increased more, numerical frequency increases from $33 \mathrm{~Hz}$ to $75 \mathrm{~Hz}$; and after feeding more than $15 \mathrm{~m} / \mathrm{min}$, with the increase of feed speed fall, increase the rate of tooth saw blade is far greater than the full frequency band saw blade increase rate, its value has been well above the in band saw blade. And then judge whether the band saw blade tooth loss, should be combined with the feed rate of regional comprehensive judgment bandsaw tooth loss situation.

\subsection{Under different load off effect of tooth number on the transverse vibration frequency of band saw blade}

The band wheel spindle speed 700PRM, sawing lumber thickness of $20 \mathrm{~mm}$, the weight of $100 \mathrm{~N}$ on the top pressure, under the saw blade spacing is $550 \mathrm{~mm}$, cutting trees for poplar, the feed speed is $15 \mathrm{~m} / \mathrm{min}$, respectively the number of teeth were $1,2,3,4,5$ of the band saw blade the data acquisition test, frequency data from power spectrum analysis, shown in Fig. 9.

Fig.9 shows that with the increase of the number of teeth out of band saw blade, saw blade vibration frequency value increases, increased from $33 \mathrm{~Hz}$ to $72 \mathrm{~Hz}$, so you can change according to the transverse vibration frequency of the saw blade, can the number of reverse inference band saw tooth loss, which can on-line monitoring saw tooth fault state fell.

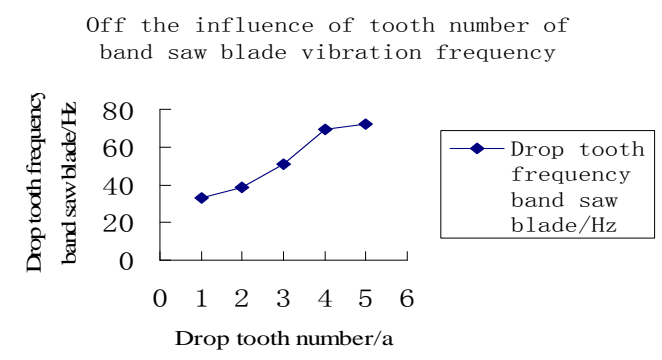

Fig.9 The different effect of tooth number on the out of band saw blade vibration

\section{Conclusion}

After the above in no-load and load of MJ3310B woodwork sawing machine saw blade vibration test and the test data processing and analysis, draw the following conclusions: 
For MJ3310A type woodworking band sawing machine using $125 \mathrm{~mm}$, width of blade, as the main factor affecting the band saw tooth loss: saw wheel speed, weight weight, feed rate.

No load when the saw wheel spindle speed, RAM weight, upper and lower saw blade spacing are adjusted to the most appropriate circumstances, determination of transverse vibration frequency between $31 \mathrm{~Hz} \sim 43 \mathrm{~Hz}$, the saw blade has produced at least 1 lost tooth defect; the feed speed under proper cutting of poplar determination of transverse vibration frequency, between $33 \mathrm{~Hz} \sim 51 \mathrm{~Hz}$, the saw blade has produced at least 1 lost tooth defect.

With the increase of the number of teeth out of band saw blade, saw blade vibration frequency increases, increases from $33 \mathrm{~Hz}$ to $72 \mathrm{~Hz}$.

Aaccording to the change of transverse vibration frequency of the saw blade, can determine the number of online bandsaw tooth loss, which can fault on-line monitoring of bandsaw blade.

\section{Funded Project}

The study was conducted by the national natural science fund of the People's Republic of China. National natural science fund project information: based on time series analysis of woodworking band saw blade tooth crack formation mechanism and prediction research and loss, item number (31570556).

\section{Reference}

[1] Fu-Zhou woodworking machine-foreign machinery industry basic situation [M]. Beijing: mechanical industry publishing house. 1989.

[2] [Soviet] thanks, Leo. Band saw into the dynamics of the cutting process influence on the technology of the [J]., (eds) woodworking machine, 1989, (4) : 38-42.

[3] Tie-Ling ZHANG. Band saw blade tension experiment on the influence of blade stability research [D]. Northeast forestry university. Library. 1988.

[4] Hua-BinWANG et al., 1989, band saw blade sawing hanging position influence on the stress distribution and stability of the saw blade width [J]. Journal of wood industry, Vol. 3, (4) : 5-11.

[5] Guo-Xi ZHU Hua-BinWANG etc. The study of Chinese modern lumber production line. Harbin, northeast forestry university press, 1989, on September 2-10.

[6] Wei Su Er-Ke XIE Eva. Band saw wheel horizontal displacement effect on the working performance of the band saw blade., (eds) woodworking machine, 1989, (2) : 30- 31. 